\title{
Household-stored drinking water quality among households of under-five children with and without acute diarrhea in towns of Wegera District, in North Gondar, Northwest Ethiopia
}

\author{
Hailemariam Feleke • Girmay Medhin • \\ Helmut Kloos • Janardhanan Gangathulasi • \\ Daniel Asrat
}

Received: 29 December 2017 / Accepted: 8 October 2018 / Published online: 23 October 2018

(C) The Author(s) 2018

\begin{abstract}
Contamination of drinking water in household water storage containers and inadequate water supplies are common public burdens in low- and middleincome countries, including towns in Wegera District, Ethiopia. Our study aimed to assess the quality of drinking water and identify factors associated with diarrhea in households with under-five (U5) children with and without diarrhea in Ambagiorgis and Gedebge towns in Wegera District. Stored drinking water samples from households with U5 children with and without diarrhea had fecal coliform (FC) counts of $59(86.8 \%)$ and 55 $(82.1 \%)(p>0.05)$ and fecal streptococci (FS) counts of $29(42.7 \%)$ and $24(35.8 \%)(p>0.05)$, respectively. The very high sanitary risk scores were $32(47.1 \%)$ and 21
\end{abstract}

H. Feleke $(\bowtie)$

Ethiopian Institute of Water Resources, Addis Ababa University, Addis Ababa, Ethiopia

e-mail: hamar35yoseph1@gmail.com

\section{G. Medhin}

Aklilu Lemma Institute of Pathobiology, Addis Ababa University, Addis Ababa, Ethiopia

\section{H. Kloos}

Department of Epidemiology and Biostatistics, University of California, San Francisco, San Francisco, CA, USA

J. Gangathulasi

Center for Environmental Management, Chennai, India

D. Asrat

Faculty of Medicine, Addis Ababa University, Addis Ababa, Ethiopia
(31.3\%) for FC $(p>0.05) ; 25(36.8 \%)$ and $3(4.5 \%)$ for FS $(p<0.001)$, respectively. Contamination of the stored drinking water samples with FS was significantly higher in households with diarrhetic U5 children in the low- and medium-risk ranges $(p<0.05)$. Water turbidity of 47 $(69.1 \%)$ and $23(34.3 \%)$ in households with U5 children with and without diarrhea, respectively, was above the permissible level $(p<0.001)$. The residual free chlorine (RFC) in all the household-stored drinking water samples was below the World Health Organization (WHO) permissible level and temperatures of all the household-stored drinking water samples were permissible. Promotion and advocacy of good stored drinking water handling practices are essential for decreasing the high risk of microbial contamination in both study areas. We recommend education interventions targeting personal hygiene and drinking water handling at the household level.

Keywords Household-stored drinking water quality . Diarrhea · Under-five children · Membrane filtration . Ethiopia

\section{Background}

About 28 in 100 people lack access to sufficient and quality drinking water globally (WHO and UNICEF 2017). The disparity in piped drinking water access between urban and rural communities is highly pronounced worldwide (MOFED 2010; WHO/UNICEF 
2015). Ethiopia met the 2015 Millennium Development target of providing drinking water from improved sources (WHO/UNICEF 2015). Nevertheless, the safe drinking water access rate in Ethiopia is one of the lowest among sub-Saharan countries (Siraj and Rao 2016).

Due to inadequate access and frequent interruptions of piped water supply (Adane et al. 2017b), drinking water is commonly stored, often for considerable lengths of time, resulting in gross contamination (Chalchisa et al. 2017). When water is handled during storage in households, it may be subjected to further contamination (WHO 2011). Microbial contamination is the most common and widespread health risk associated with drinking water (Daud et al. 2017), especially among young children, who have the highest diarrhea rates worldwide (Nelson et al. 2012). Water collected from sources with good microbial quality may become contaminated during storage in households (Tadesse et al. 2010; Adane et al. 2017b).

Safe drinking water does not cause any significant risk to health over a lifetime of consumption (WHO 2011). According to the WHO microbiological guidelines (WHO 2004), coliform bacteria must not be detected in $100 \mathrm{ml}$ samples of water for the water to be considered safe; their detection in water indicates pathogenic bacterial contamination (Chalchisa et al. 2017).

The physical quality of drinking water can be measured by its turbidity level; high turbidity can result in increased microbiological and chemical contamination (Mann et al. 2007). Microbial quality of drinking water has been tested using surrogate organisms (Sinclair et al. 2012), including fecal coliform (FC) and fecal streptococci (FS). Testing of drinking water stored in households is important to ascertain its physicochemical and microbial quality at the time of consumption (WHO 2003).

The Ethiopian Demographic and Health Survey reported that $97 \%$ of urban households in Ethiopia have access to an improved source of drinking water (CSA and ICF 2016). Nevertheless, no reliable information is available on the readability of drinking water quality reports (Roy et al. 2015). Although diarrhea is mainly a water-related disease, the difference in diarrhea prevalence between urban areas, with nearly universal access to improved water, and rural areas, with only $57 \%$ improved water access, is slight in Ethiopia (CSA and ICF 2016).
The Ethiopian Demographic and Health Survey reported that for the last 10 years, diarrhea prevalence was highest in Amhara Region after Gambela and Southern Nations, Nationalities, and People's Regions (CSA and ICF 2016). In collaboration with the Health and Finance offices of Wegera District, the Water, Sanitation, and Hygiene (WASH) project is working on well and spring water development and latrine construction activities in Wegera District. The UNICEF-led USAID Nutrition and WASH project is also working on increasing the utilization of quality nutrition services for young children, improving the utilization of WASH products and services, and other related activities in Wegera District. The WASH project has developed well and spring water in both rural and urban settings in the District as part of the Millennium Development Goal target for urban water supply coverage in towns of Wegera District.

The objective of our study was to assess the quality of stored drinking water in households with children under the age of 5 years (U5) with and without diarrhea in Ambagiorgis and Gedebge towns of Wegera District in Amhara Region, Ethiopia. The findings of this study may assist Ethiopian water officials, primary health-care institutes, and health policymakers in designing programs for increasing awareness about household water handling practices, hygiene, sanitation, and protection and treatment of household-stored water.

\section{Materials and methods}

\section{Study design}

A community-based survey was conducted in Ambagiorgis and Gedebge towns of Wegera District from June to October 2016 with the aim of assessing the quality of household-stored drinking water in households with U5 children with and without acute diarrhea. Wegera District is located in northwestern Ethiopia (Fig. 1). Based on the 2007 Ethiopian census, the average family size was 4 and the total number of households inhabiting Ambagiorgis and Gedebge towns was 3629 and 1650, respectively (CSA 2008). The main drinking water sources are protected springs, protected hand pumps, and 


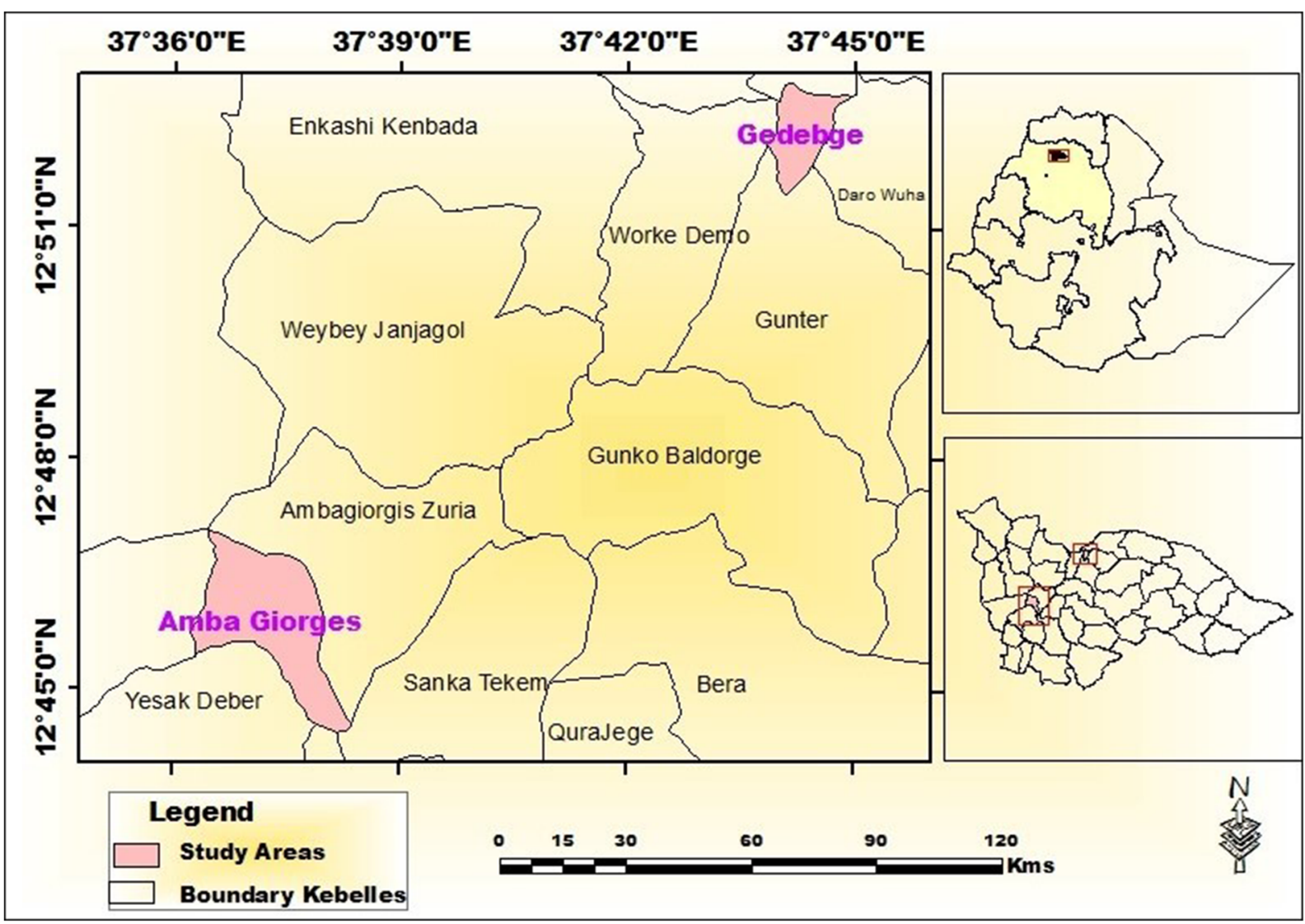

Fig. 1 Location of Ambagiorgis and Gedebge towns in Wegera District

protected dug wells. All household-stored drinking water collected from protected water sources and stored in households with at least one U5 child who used the protected water sources was included in the survey. Based on previous water quality surveys in the region (CSA and ICF 2016), Ambagiorgis and Gedebge towns were selected for study.

Sample size determination and sampling procedure

Based on a similar study, we assumed that minimal prevalence of the fecal indicator among diarrhetic U5 children would be $71 \%$ and among non-diarrheic $90 \%$ (Boru et al. 2013). The alpha error was set at $5 \%$ and the power of the study at $80 \%$. The required sample size was calculated to be 68 for diarrhetic and 67 for nondiarrhetic children, considering $1.5 \%(1 / 69)$ and $2.9 \%$ $(2 / 69)$ non-response rate for the diarrhetic and nondiarrhetic groups, respectively. Hence, 92 children from
Ambagiorgis and 43 children from Gedebge towns were enrolled in the study.

Data collection tools and procedures

Data were collected by using pretested questionnaires, sanitary inspection checklists (Howard 2002) (Tables 1 and 2), and a rapid water testing kit (Messer and Dufour 1998). A 150-ml stored drinking water sample was collected in a sterile glass bottle from every participating household with U5 children. The physicochemical and microbial analysis was done using standard analytical techniques and instruments such as a $\mathrm{pH} 11$ meter (Wagtech) to measure $\mathrm{pH}$ and temperature, a Potalab turbidity meter to measure turbidity, and a color comparator to measure residual free chlorine. Wagtech field test kits were used to detect $\mathrm{FC}$ as yellow color on membrane lauryl sulfate broth (MLSB) and FS as red color on enterococcus agar. Turbidity, $\mathrm{pH}$, temperature, and residual free chlorine were measured on site. 
Table 1 Checklist for the identification of sanitary inspection risk factors

\begin{tabular}{|c|c|}
\hline Question & Answer \\
\hline 1. Is drinking water kept in a separate container? & $\mathrm{Y} / \mathrm{N}$ \\
\hline $\begin{array}{l}\text { 2. Is drinking water kept above floor level and } \\
\text { away from contamination? }\end{array}$ & $\mathrm{Y} / \mathrm{N}$ \\
\hline $\begin{array}{l}\text { 3. Do water containers have a narrow } \\
\text { mouth/opening? }\end{array}$ & $\mathrm{Y} / \mathrm{N}$ \\
\hline 4. Do containers have a lid/cover? & $\mathrm{Y} / \mathrm{N}$ \\
\hline 5. Was the lid/cover in place at time of visit & $\mathrm{Y} / \mathrm{N}$ \\
\hline 6. How is water taken from the container? & $\begin{array}{c}\text { Pouring or } \\
\text { dipping }\end{array}$ \\
\hline $\begin{array}{l}\text { 7. Is a clean utensil used to draw water from the } \\
\text { container? }\end{array}$ & $\mathrm{Y} / \mathrm{N}$ \\
\hline $\begin{array}{l}\text { 8. Is the utensil used to draw water from the } \\
\text { container kept away from surfaces and stored in } \\
\text { a hygienic manner? }\end{array}$ & $\mathrm{Y} / \mathrm{N}$ \\
\hline $\begin{array}{l}\text { 9. Is the inside of the drinking water container } \\
\text { clean? }\end{array}$ & $\mathrm{Y} / \mathrm{N}$ \\
\hline $\begin{array}{l}\text { 10. Is the outside of the drinking water container } \\
\text { clean? }\end{array}$ & $\mathrm{Y} / \mathrm{N}$ \\
\hline
\end{tabular}

Table 2 Sociodemographic characteristics of households with under-five children in Ambagiorgis and Gedebge towns

\begin{tabular}{|c|c|c|c|}
\hline Variables & $\begin{array}{l}\text { U5 children with } \\
\text { diarrhea }(n=68)\end{array}$ & $\begin{array}{l}\text { U5 children without } \\
\text { diarrhea }(n=67)\end{array}$ & $\begin{array}{l}p \\
\text { value }\end{array}$ \\
\hline \multicolumn{4}{|c|}{ Age of caregivers (years) } \\
\hline$<25$ & $9(13.2 \%)$ & $15(22.4 \%)$ & \\
\hline $25-34$ & $48(70.6 \%)$ & $42(62.7 \%)$ & 0.379 \\
\hline$>34$ & $11(16.2 \%)$ & $10(14.9 \%)$ & \\
\hline \multicolumn{4}{|c|}{ Education of caregivers } \\
\hline Illiterate & $39(57.4 \%)$ & $23(34.3 \%)$ & $0.007 *$ \\
\hline Literate & $29(42.6 \%)$ & $44(65.7 \%)$ & \\
\hline \multicolumn{4}{|c|}{ Monthly household income (\$USD ${ }^{\mathrm{a}}$ ) } \\
\hline$\leq 47 \mathrm{USD}$ & $43(63.2 \%)$ & $31(46.3 \%)$ & \\
\hline$>47 \mathrm{USD}$ & $25(36.8 \%)$ & $36(53.7 \%)$ & 0.048 \\
\hline \multicolumn{4}{|c|}{ Household size } \\
\hline $\begin{aligned} \leq & \text { Four and } \\
& \text { less than } \\
& \text { four }\end{aligned}$ & $27(39.7 \%)$ & $34(50.7 \%)$ & \\
\hline $\begin{array}{l}>\text { Five and } \\
\text { above }\end{array}$ & $41(60.3 \%)$ & $33(49.3 \%)$ & 0.197 \\
\hline \multicolumn{4}{|c|}{ Water source } \\
\hline $\begin{array}{l}\text { Protected } \\
\text { spring }\end{array}$ & $26(38.2 \%)$ & $7(10.4 \%)$ & \\
\hline Tap water & $42(61.8 \%)$ & $60(89.6 \%)$ & $0.001 *$ \\
\hline
\end{tabular}

${ }^{\text {a } U S ~ d o l l a r s, ~} * p$ value $<0.05$
Data quality management and analysis

The quality of the data was controlled by using questionnaires and sanitary inspection checklists based on WHO standard methods for household surveys (WHO and UNICEF 2006). Distilled and sterile water was used as a quality control for the membrane filtration technique. The instruments were calibrated before testing the physicochemical parameters. Water samples were collected and transported to the Angereb laboratory unit in Gondar Town for microbial water quality analysis within $4 \mathrm{~h}$. During transportation, the samples were stored below $4{ }^{\circ} \mathrm{C}$ using an icebox. Descriptive statistics, including means, proportions, and percentages, were used, followed by chi-square tests to compare the quality of stored drinking water among households with U5 children with and without diarrhea. The FC and FS counts were compared and interpreted using the WHO guidelines for drinking water (WHO 2004).

\section{Operational definitions}

Diarrhea: having two or more loose stools a day in the 2 weeks before the interviews.

Protected spring: a spring that is properly protected by one or two masonry boxes and has a distribution site near the boxes (Mengesha et al. 2017).

Protected well: a well that is properly constructed with masonry and internally plastered at least $3 \mathrm{~m}$ deep and with an electric pump at the top (Mengesha et al. 2017).

Residual free chlorine: the concentration of chlorine in stored drinking water present as dissolved gas $\left(\mathrm{Cl}_{2}\right)$, hypochlorous acid $(\mathrm{HOCl})$, or hypochlorite ion $\left(\mathrm{OCl}^{-}\right)$.

Stored drinking water: water that is intended for drinking and is stored in a container.

\section{Results and discussion}

\section{Sociodemographic characteristics}

The ages of the caregivers in households with diarretic and non-diarrhetic U5 children were similar $(p>0.05)$. Significantly more caregivers in households with U5 children without diarrhea were literate 
$(p<0.05)$ and had higher monthly incomes than those in households with diarrhea cases $(p<0.05)$. The use of tap water was also associated with the absence of diarrhea $(p<0.01)$ (Table 2$)$.

Microbial quality of household-stored drinking water

The contamination of $59(86.8 \%)$ of the drinking water samples from households of U5 diarrhetic children with low (16.2\%), medium (47.1\%), high (13.2\%), and very high $(10.3 \%)$ risk of FC concentrations and $55(82.1 \%)$ of the samples from households of U5 non-diarrhetic children with low (22.4\%), medium (44.8\%), high $(9.0 \%)$, and very high $(6.0 \%)$ risk of FC concentrations was similar $(p>0.05)$. However, FS concentrations of water samples were significantly higher in households with diarrhetic children in the low and medium sanitary risk categories $(p<0.05)$ (Table 3$)$.

Contamination risk levels of household-stored drinking water samples

Using FC and FS counts as a proxy to determine overall health risk, 41 (60.3\%), 6 (8.8\%), 10 (14.7\%), and 2 $(2.9 \%)$ of the drinking water samples from households with U5 children with diarrhea $(p<0.001)$ and 22 (32.8\%), $22(32.8 \%), 11(16.4 \%)$, and $0(0.0 \%)$ of the samples from households with U5 children without diarrhea $(p<0.01)$ had very high, high, medium, and low sanitary risk scores for FC, respectively (Table 4, Figs. 2 and 3$)$. Twenty-five (36.8\%), 3 (4.4\%), 1 (1.5\%), and 0 $(0.0 \%)$ of the drinking water samples from households with U5 children with diarrhea $(p<0.001)$ and $4(6.0 \%)$, $3(4.5 \%), 17(25.4 \%)$, and $0(0.0 \%)$ of the samples from households of U5 children without diarrhea $(p<0.001)$ also had very high, high, medium, and low sanitary risk scores for FS, respectively (Table 4, Figs. 4 and 5).

Physicochemical analysis of stored drinking water samples

Forty-seven $(69.1 \%)$ of the drinking water samples from households with U5 children with diarrhea and 23 (34.3\%) of the samples from households with U5 children without diarrhea had turbidity values above the WHO permissible level $(p<0.001)$. Five $(7.4 \%)$ of the drinking water samples from households with U5 children with diarrhea and $4(6.0 \%)$ of the samples from households with U5 children without diarrhea had $\mathrm{pH}$ above the WHO permissible level $(p>0.05)$. None of the household drinking water samples had permissible amounts of residual free chlorine, but the temperatures of all the household-stored drinking water samples were in conformity with the WHO standards.

The use of protected spring water sources was significantly higher in households with U5 children with diarrhea than in households with U5 children without diarrhea. A study in Kenya revealed that total coliform was abundant in most of the spring water sources studied including protected springs, whereas fecal coliform was present in $29 \%$ of spring water sources. The authors noted that the presence of coliform may pose a high risk of water-borne diarrhea diseases (Simiyu et al. 2009). A study on the effect of improved water supplies on U5 diarrhea prevalence showed that improved water supply reduced diarrhea in U5 children by only $11 \%$ (Cha et al. 2015). The present study may raise questions about the quality of WHO-recommended improved water sources (protected springs and protected wells).

The percentage of caregivers who were illiterate was significantly higher in households with U5 children with diarrhea than without diarrhea. An observational casecontrol study in Jamaica showed that children of caregivers with low knowledge scores about the prevention and treatment of diarrhea were at increased risk of presenting with gastroenteritis (Bachrach and Gardner 2002). Our study reveals a need to enhance caregivers' education to protect under-five children from diarrhea and associated diseases.

WHO recommends that $100 \mathrm{ml}$ samples of ready-todrink water be free from microbial indicator organisms (WHO 2011). The majority of our household-stored drinking water samples were grossly contaminated with FC or FS. Consistent with our finding, the microbiological quality of drinking water in the Rift Valley area of Ethiopia has been reported as very poor (Amenu et al. 2014). Furthermore, a study in Myanmar revealed that $94 \%$ of household-stored drinking water samples were contaminated with thermotolerant coliforms (Myint et al. 2015).

The high level of drinking water contamination in our study might be due to contamination at the source, inadequate chlorine treatment, and improper water handling at the household level. Inappropriate water handling, as well as unhygienic activities, and environmental contamination appear to be the contributors to water contamination at the point of use. A finding in Addis Ababa slum areas revealed that shared sanitation facilities were significantly associated with the occurrence of 
Table 3 Fecal coliform and fecal streptococci counts per $100 \mathrm{ml}$ of stored drinking water samples in households with under-five children with and without diarrhea

\begin{tabular}{|c|c|c|c|c|c|c|c|}
\hline & \multicolumn{7}{|c|}{ Fecal coliform counts per $100 \mathrm{ml}$ sample of stored drinking water } \\
\hline & $0 \mathrm{n}(\%)$ & $1-9 \mathrm{n}(\%)$ & $10-99$ n $(\%)$ & $100-999$ n $(\%)$ & $\geq 1000 n(\%)$ & Total $n(\%)$ & $p$ \\
\hline Water samples & & & & & & & 0.454 \\
\hline U5 children with diarrhea $(n=68)$ & $9(13.2)$ & $11(16.2)$ & $32(47.1)$ & $9(13.2)$ & $7(10.3)$ & $59(86.8)$ & \\
\hline U5 children without diarrhea $(n=67)$ & $12(17.9)$ & $15(22.4)$ & $30(44.8)$ & $6(9.0)$ & $4(6.0)$ & $55(82.1)$ & \\
\hline Risk category* & Conformed* & Low risk & Medium risk & High risk & Very high risk & & \\
\hline \multirow[t]{3}{*}{$p$ value $(p)$} & & 0.970 & 0.488 & 0.310 & 0.264 & & \\
\hline & \multicolumn{7}{|c|}{ Fecal streptococci counts per $100 \mathrm{ml}$ sample of stored drinking water } \\
\hline & $0 n(\%)$ & $1-9 n(\%)$ & $10-99 n(\%)$ & $100-999 n(\%)$ & $\geq 1000 n(\%)$ & Total $n(\%)$ & $p$ \\
\hline Water samples & & & & & & & 0.417 \\
\hline U5 children with diarrhea $(n=68)$ & $39(57.4)$ & $1(1.5)$ & $23(33.8)$ & $3(4.4)$ & $2(2.9)$ & $29(42.7)$ & \\
\hline U5 children without diarrhea $(n=67)$ & $43(64.2)$ & $8(11.9)$ & $11(16.4)$ & $5(7.5)$ & $0(0.0)$ & $24(35.8)$ & \\
\hline Risk category & Conformed* & Low risk & Medium risk & High risk & Very high risk & & \\
\hline$p$ value & & 0.036 & 0.048 & 0.586 & 0.143 & & \\
\hline
\end{tabular}

*Conforming with WHO standards (WHO 2011)

acute diarrhea and hand washing with soap before preparing food and after defecation were the most important of the recommended times for preventing the occurrence of acute diarrhea in the slums of Addis Ababa, Ethiopia (Adane et al. 2017a, c).

Using the WHO water standard (WHO 2011), the current study found that the microbial quality of household-stored drinking water in most of the stored drinking water samples from both households with U5 children with diarrhea and households with U5 children without diarrhea was contaminated with FC. Consistent with our findings, a study in Canada showed that exposure to water-borne pathogens and lack of sanitation contributed to major health issues in some communities (Metcalfe et al. 2011). Similarly, a study in southern Ethiopia identified FC in $80 \%$ of drinking water samples, with counts ranging between 0.67 and $266.67 \mathrm{CFU} / 100 \mathrm{ml}$ (Yasin et al. 2015). A study on water handling practices and levels of contamination in another highland town in Ethiopia reported that all household-stored drinking water samples were positive for total coliform and 33\% for FC (Sharma et al. 2013). In our study, 29 (43\%) of the stored drinking water samples among households with U5 children with diarrhea and 24 (36\%) of the samples among households with under-five children without diarrhea were contaminated by FS. These rates are lower than those recorded by Abbas et al., who found $67 \%$ of their samples positive for FS in a community in Pakistan (Abbas et al. 2007). A study in Nepal reported that $15 \%$ of the tap water samples in an urban area in Nepal were contaminated with FS (Pant et al. 2016). A study in China recorded $32.3 \%$ of spring water samples contaminated with FS (Wei et al. 2017). According to research findings in Ghana, FC and FS were consistently present in the water sources in a peri-urban area in Ghana, suggesting anthropogenic pollution (Boamah et al. 2011). The contamination rates in our study were in the middle range of those found in the studies, indicating the need for continuous monitoring and surveillance of sources and good practices for handling household-stored drinking water.

According to the WHO guidelines, drinking water should contain $>0.5 \mathrm{mg} / \mathrm{l}$ RFC. However, we found that all the household-stored drinking water samples had smaller amounts of RFC than necessary to safeguard against the risk of subsequent microbial contamination. In another small Ethiopian town, $85 \%$ of stored water samples had no RFC (Sharma et al. 2013). The importance of RFC in stored drinking water was emphasized by several researchers (Chiller et al. 2006; Arnold and Colford 2007; Harshfield et al. 2012; Mengistie et al. 2013). A study in Tanzania concluded that chlorine disinfection was effective against both water-borne bacteria and viruses (Mohamed et al. 2015). A trial study in Bangladesh revealed that E. coli concentration in household-stored drinking water was lowest when consumers used chlorine (Luoto et al. 2011). The present study demonstrates the need to treat water to meet acceptable RFC levels to decrease the risk of contamination of stored drinking water.

Water temperatures were within the WHO permissible range (between 15 and $20{ }^{\circ} \mathrm{C}$ ) due to the high 
Table 4 Sanitary inspection risk scores in relation to fecal coliform and fecal streptococci counts per $100 \mathrm{ml}$ sample of stored drinking water of households with under-five children with and without diarrhea

Fecal coliform counts per $100 \mathrm{ml}$ sample of household-stored drinking water

\begin{tabular}{lllllll}
\hline Risk scores & Risk score & 0 & $1-9$ & $10-99$ \\
$n(\%)$ & $n(\%)$ & $100-999 n(\%)$ & $\geq 1000 n(\%)$ & $\begin{array}{l}\text { Total } \\
n(\%)\end{array}$ & $\begin{array}{l}p \text { value } \\
\end{array}$ \\
\hline
\end{tabular}

U5 diarrhetic children with $(n=68)$

\begin{tabular}{|c|c|c|c|c|c|c|c|c|}
\hline $0-2$ & Low & $0(0.0)$ & $0(0.0)$ & $0(0.0)$ & $0(0.0)$ & $2(2.9)$ & $2(2.9)$ & \\
\hline $3-5$ & Medium & $2(2.9)$ & $4(5.9)$ & $0(0.0)$ & $5(7.4)$ & $1(1.5)$ & $10(14.7)$ & \\
\hline $6-8$ & High & $7(10.3)$ & $2(2.9)$ & $0(0.0)$ & $1(1.5)$ & $3(7.4)$ & $6(8.8)$ & \\
\hline $9-10$ & Very high & $0(0.0)$ & $5(7.4)$ & $32(47.1)$ & $3(4.4)$ & $1(1.5)$ & $41(60.3)$ & $<0.001$ \\
\hline Total & & 9 & 11 & 32 & 9 & 7 & 59 & \\
\hline \multicolumn{9}{|c|}{ U5 non-diarrhetic children $(n=67)$} \\
\hline $0-2$ & Low & $1(1.5)$ & $0(0.0)$ & $0(0.0)$ & $0(0.0)$ & $0(0.0)$ & $0(0.0)$ & \multirow{4}{*}{0.005} \\
\hline $3-5$ & Medium & $6(9.0)$ & $6(9.0)$ & $1(1.5)$ & $2(3.0)$ & $2(3.0)$ & $11(16.4)$ & \\
\hline $6-8$ & High & $5(7.5)$ & $1(1.5)$ & $16(23.9)$ & $3(4.5)$ & $2(3.0)$ & $22(32.8)$ & \\
\hline $9-10$ & Very high & $0(0.0)$ & $0(0.0)$ & $21(31.3)$ & $1(1.5)$ & $0(0.0)$ & $22(32.8)$ & \\
\hline Total & & 12 & 7 & 38 & 6 & 4 & 55 & \\
\hline \multicolumn{9}{|c|}{ Fecal streptococci counts per $100 \mathrm{ml}$ sample of household-stored drinking water } \\
\hline Risk score & Risk score & $\begin{array}{l}0 \\
n(\%)\end{array}$ & $\begin{array}{l}1-9 \\
n(\%)\end{array}$ & $\begin{array}{l}10-99 \\
n(\%)\end{array}$ & $\begin{array}{l}100-999 \\
n(\%)\end{array}$ & $\begin{array}{l}\geq 1000 \\
n(\%)\end{array}$ & $\begin{array}{l}\text { Total } \\
n(\%)\end{array}$ & $p$ value \\
\hline \multicolumn{9}{|c|}{ U5 diarrhetic children $(n=68)$} \\
\hline $0-2$ & Low & $2(2.9 \%)$ & $0(0.0)$ & $0(0.0)$ & $0(0.0)$ & $0(0.0)$ & $0(0.0)$ & \multirow{5}{*}{$<0.001$} \\
\hline $3-5$ & Medium & $29(42.7)$ & $0(0.0)$ & $0(0.0)$ & $1(1.5 \%)$ & $0(0.0)$ & $1(1.5)$ & \\
\hline $6-8$ & High & $8(11.8 \%)$ & $1(1.5 \%)$ & $1(1.5 \%)$ & $1(1.5 \%)$ & $0(0.0)$ & $3(4.4)$ & \\
\hline $9-10$ & Very high & $0(0.0)$ & $0(0.0)$ & $25(36.8 \%)$ & $0(0.0)$ & $0(0.0)$ & $25(36.8 \%)$ & \\
\hline Total & & 39 & 1 & 26 & 2 & 0 & 29 & \\
\hline \multicolumn{9}{|c|}{ U5 non-diarrhetic children $(n=67)$} \\
\hline $0-2$ & Low & $23(34.3 \%)$ & $0(0.0)$ & $0(0.0)$ & $0(0.0)$ & $0(0.0)$ & $0(0.0)$ & \multirow{4}{*}{$<0.001$} \\
\hline $3-5$ & Medium & $15(22.4 \%)$ & $3(4.5 \%)$ & $11(16.4 \%)$ & $3(4.5 \%)$ & $0(0.0)$ & $17(25.4)$ & \\
\hline $6-8$ & High & $5(7.5 \%)$ & $1(1.5 \%)$ & $1(1.5 \%)$ & $1(1.5 \%)$ & $0(0.0)$ & $3(4.5)$ & \\
\hline $9-10$ & Very high & $0(0.0)$ & $0(0.0)$ & $3(4.5)$ & $1(1.5 \%)$ & $0(0.0)$ & $4(6.0 \%)$ & \\
\hline Total & & 43 & 4 & 15 & 5 & 0 & 24 & \\
\hline
\end{tabular}

altitude of the study sites (Ambagiorgis is at around $2900 \mathrm{~m}$ and Gedebge at $2700 \mathrm{~m}$ altitude).

Our study showed that almost $70 \%$ of the studied households with U5 children with diarrhea and $23(34 \%)$ of the households with U5 children without diarrhea had turbid stored water that exceeded the WHO permissible limit for turbidity. A study in Jimma Zone in Ethiopia recorded turbidity of drinking water samples up to $65 \mathrm{NTU}$ (Yasin et al. 2015). Researchers (Tinker et al. 2010; Hsieh et al. 2015) have demonstrated an association between water turbidity and emergency department visits for gastrointestinal illness.
The poor water quality widely observed in storage vessels might be due to lack of proper procedures for retrieving water from storage containers. The behavioral and hygienic practices of communities may contribute to the burden of drinking water contamination. A report from Addis Ababa slums revealed that retrieving water from water storage vessels using handle-less vessels was associated with acute diarrhea (Adane et al. 2017b). A study in Zambia showed that stored water in households that implemented treatment and safe storage measures was significantly less contaminated with Escherichia coli than water in households without such measures (Quick et al. 2002). A systematic review in low- and 


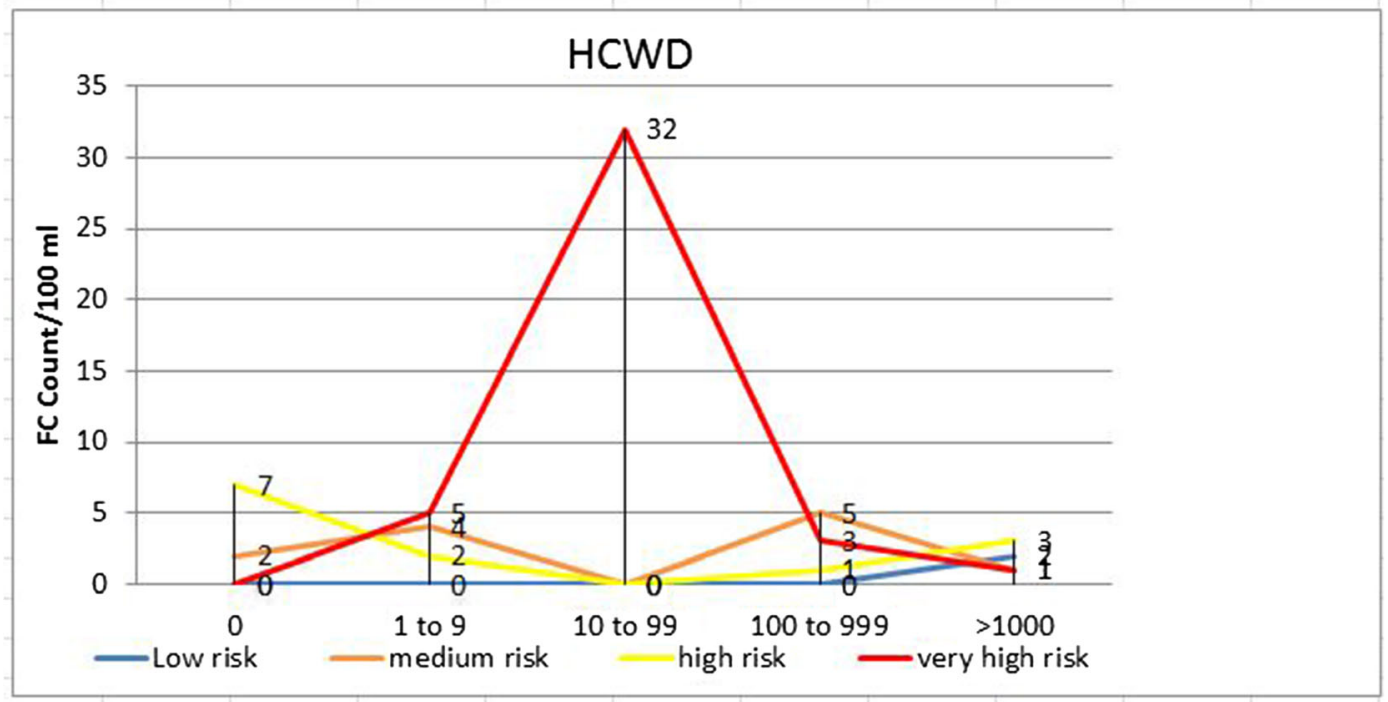

Fig. 2 Sanitary inspection risk scores and fecal coliform counts (CFU/100 ml) in households with U5 children with diarrhea (HCWD)

middle-income countries concluded that few previous studies examined stored water quality and sanitary risk (Bain et al. 2014) and their roles in acute diarrhea infection.

Sanitary risk scores based on our sanitary inspections of household vessels ranged from low to very high, with most vessels having medium and very high sanitary risk scores for FS and FC. Similarly, a study conducted in Nyala Town, Sudan, and Bahr Dar Town, Ethiopia, found nearly half $(46 \%)$ of the water samples examined to have very high levels of FC (Abdelrahman and Eltahir 2011; Tabor et al. 2011). A study in northeastern Ethiopia showed that $138(72.0 \%)$ households in which people drew water from a container by dipping were at high risk of $\mathrm{FC}$ (Tiku et al. 2003).

It is possible that microbial qualities and physicochemical indicators of drinking water quality are differentially informative of diarrhea risk in various settings (Strauss et al. 2001). However, our study revealed that

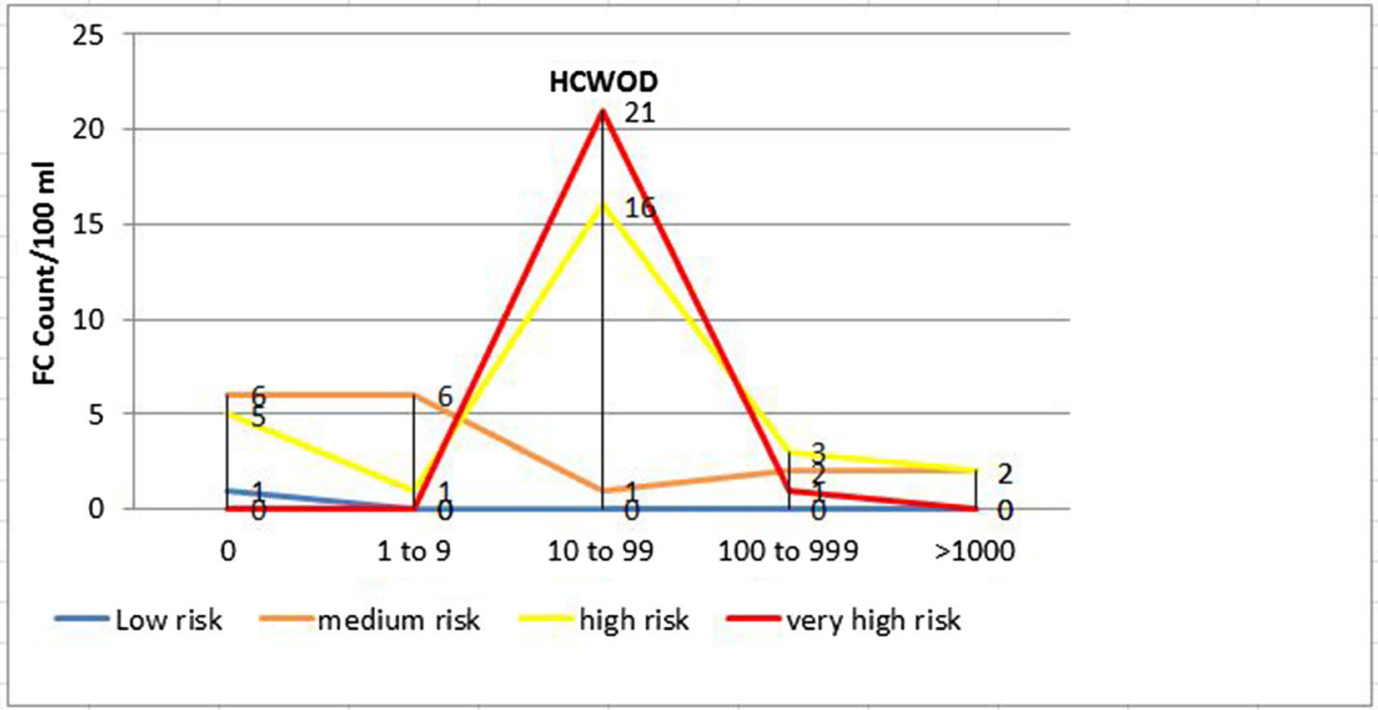

Fig. 3 Sanitary inspection risk scores and fecal coliform count (CFU/100 ml) in households with U5 children without diarrhea (HCWOD) 


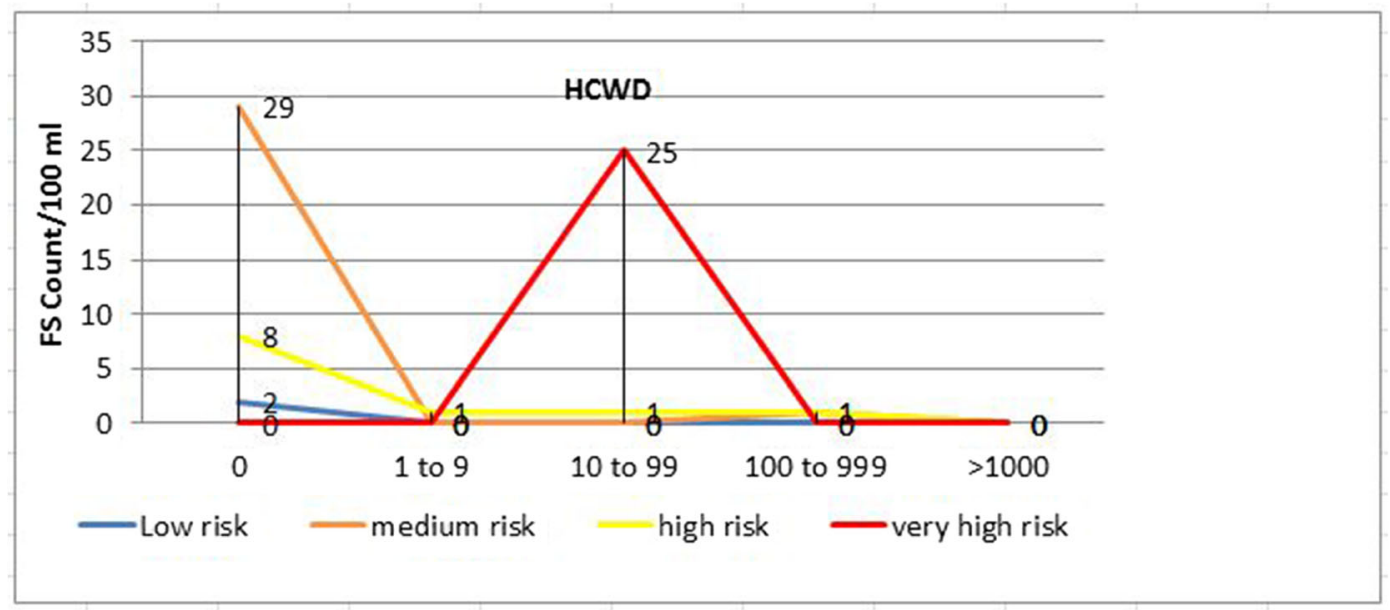

Fig. 4 Sanitary inspection risk scores and fecal streptococci counts (CFU/100 ml) in households with U5 children with diarrhea (HCWD)

FS contamination and higher turbidity of householdstored drinking water are associated with diarrhea in U5 children $(p<0.05)$ within the context of inadequate supply and poor water quality conditions that are typical of Wegera District.

\section{Conclusions}

This study found that household-stored drinking water was grossly contaminated with FC and FS in both households with U5 children with diarrhea and households with U5 children without diarrhea in the northwestern Ethiopian highlands. FS contamination at lowand medium-risk categories and turbidity of householdstored drinking water were significantly higher in households with U5 children with diarrhea than in households with U5 children without diarrhea. No permissible amounts of RFC were detected in any of the water samples tested. Frequent exposure to stored drinking water that does not conform to WHO standard may result in diarrhea among under-five children. We recommend that the local authorities implement interventions focused on the provision of safe water supplies, behavioral change in personal hygiene and drinking water handling practices, and the protection and treatment of household-stored water. These measures can improve the microbial quality by effectively preventing coliforms and pathogenic contaminants from entering the ready-to-drink water supply. We recommend that further research be carried out on health aspects of householdstored drinking water handling and use in communities

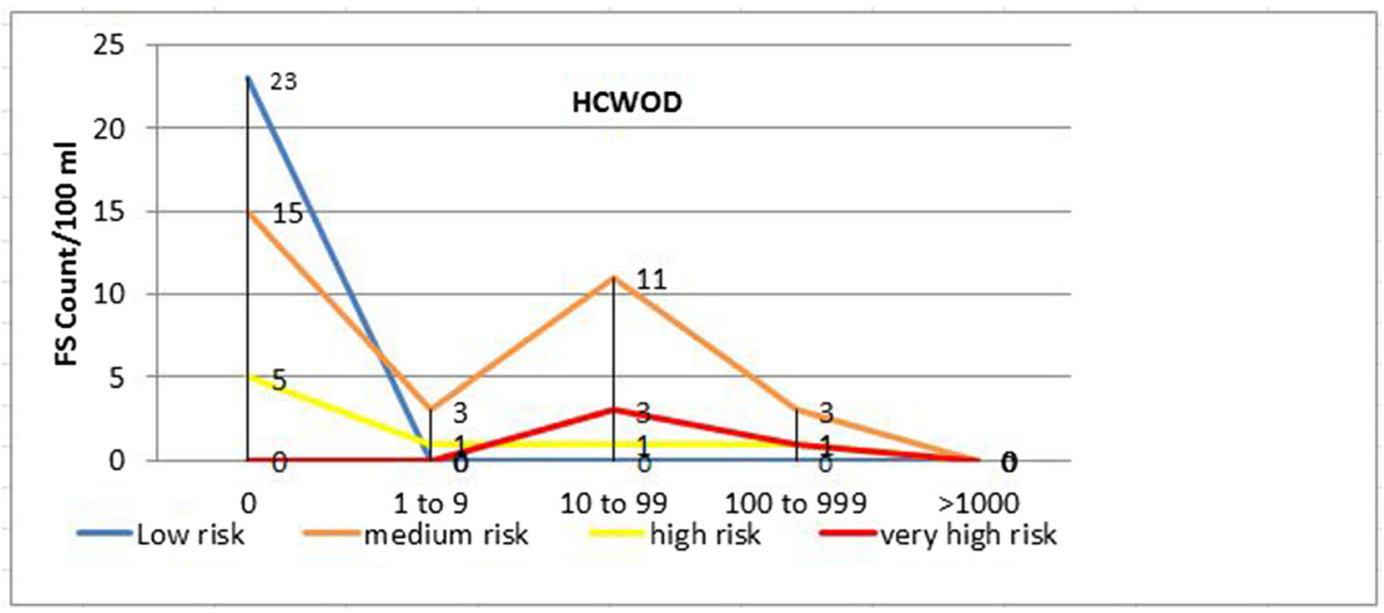

Fig. 5 Sanitary inspection risk scores and fecal streptococci counts $(\mathrm{CFU} / 100 \mathrm{ml})$ in households with U5 children without diarrhea (HCWOD) 
with different water sources and socioeconomic situations and that the WASH and other water/sanitation programs consider this issue in their behavioral intervention programs.

Acknowledgements The authors would like to acknowledge the Ethiopian Institute of Water Resources, Addis Ababa University, Assosa University, USAID, and the University of Connecticut for funding this project. We also acknowledge Wegera District Water Development Bureau and Gondar Town Water and Sewerage Authority for facilitating the laboratory work and want to thank Ann Byers for editing the manuscript at short notice.

Funding information This work was supported by USAID through the USAID/HED funded grant in the Africa-US Higher Education Initiative-HED 052-9740-ETH-11-01.

\section{Compliance with ethical standards}

Ethical clearance Ethical approval was obtained from the Ethiopian Public Health Institute in Addis Ababa and a study permit from the Wegera District Health and Water Development bureaus was obtained prior to data collection. Written consent for the interviews was given by the respondents enrolled in the survey. Oral rehydration solution was given to U5 children with diarrhea at the time of the survey.

Open Access This article is distributed under the terms of the Creative Commons Attribution 4.0 International License (http:// creativecommons.org/licenses/by/4.0/), which permits unrestricted use, distribution, and reproduction in any medium, provided you give appropriate credit to the original author(s) and the source, provide a link to the Creative Commons license, and indicate if changes were made.

\section{References}

Abbas, N., Baig, I. A., \& Shakoori, A. R. (2007). Faecal contamination of drinking water from deep aquifers in Multan, Pakistan. Pakistan Journal of Zoology, 39, 271.

Abdelrahman, A. A., \& Eltahir, Y. M. (2011). Bacteriological quality of drinking water in Nyala, South Darfur, Sudan. Environ Monit Assess, 175, 37-43.

Adane, M., Mengistie, B., Kloos, H., Medhin, G., \& Mulat, W. (2017a). Sanitation facilities, hygienic conditions, and prevalence of acute diarrhea among under-five children in slums of Addis Ababa, Ethiopia: baseline survey of a longitudinal study. PLoS One, 12, e0182783.

Adane, M., Mengistie, B., Medhin, G., Kloos, H., \& Mulat, W. (2017b). Piped water supply interruptions and acute diarrhea among under-five children in Addis Ababa slums, Ethiopia: a matched case-control study. PLoS One, 12, e0181516.
Adane, M., Mengistie, B., Mulat, W., et al. (2017c). The most important recommended times of hand washing with soap and water in preventing the occurrence of acute diarrhea among children under five years of age in slums of Addis Ababa, Ethiopia. Journal of Community Health, 43, 400405.

Amenu, K., Spengler, M., André, M., \& Zárate, A. V. (2014). Microbial quality of water in rural households of Ethiopia: implications for milk safety and public health. Journal of Health, Population, and Nutrition, 32, 190.

Arnold, B. F., \& Colford Jr., J. M. (2007). Treating water with chlorine at point-of-use to improve water quality and reduce child diarrhea in developing countries: a systematic review and meta-analysis. The American Journal of Tropical Medicine and Hygiene, 76, 354-364.

Bachrach, L. R., \& Gardner, J. M. (2002). Caregiver knowledge, attitudes, and practices regarding childhood diarrhea and dehydration in Kingston, Jamaica. Rev Panam Salud Pública, 12, 37-44.

Bain, R., Cronk, R., Wright, J., Yang, H., Slaymaker, T., \& Bartram, J. (2014). Fecal contamination of drinking-water in low-and middle-income countries: a systematic review and meta-analysis. PLoS Medicine, 11, e1001644.

Boamah, V. E., Gbedema, S. Y., Adu, F., \& Ofori-Kwakye, K. (2011). Microbial quality of household water sources and incidence of diarrhoea in three peri-urban communities in Kumasi, Ghana. Journal of Pharmaceutical Sciences and Research, 3, 1087-1091.

Boru, W. G., Omollo, J., Abade, A., et al. (2013). Aetiology and factors associated with bacterial diarrhoeal diseases amongst urban refugee children in Eastleigh, Kenya: a case control study. African Journal of Laboratory Medicine, 2, 1-6.

Cha, S., Kang, D., Tuffuor, B., Lee, G., Cho, J., Chung, J., Kim, M., Lee, H., Lee, J., \& Oh, C. (2015). The effect of improved water supply on diarrhea prevalence of children under five in the Volta region of Ghana: a cluster-randomized controlled trial. International Journal of Environmental Research and Public Health, 12, 12127-12143.

Chalchisa, D., Megersa, M., \& Beyene, A. (2017). Assessment of the quality of drinking water in storage tanks and its implication on the safety of urban water supply in developing countries. Environmental Systems Research, 6, 12. https://doi.org/10.1186/s40068-017-0089-2.

Chiller, T. M., Mendoza, C. E., Lopez, M. B., Alvarez, M., Hoekstra, R. M., Keswick, B. H., \& Luby, S. P. (2006). Reducing diarrhoea in Guatemalan children: randomized controlled trial of flocculant-disinfectant for drinking-water. Bulletin of the World Health Organization, 84, 28-35.

CSA (2008). Summary and statistical report of the 2007 population and housing census. CSA (2008). Addis Ababa Ethiop Fed Democr Repub Ethiop Popul Census Comm https://www.ethiopianreview.com/pdf/001/Cen2007 firstdraft(1).pdf. Accessed Nov 2017.

CSA, ICF. (2016). Central Statistical Agency. Ethiopian Demographic and Health Survey 2016. Addis Ababa: CSA and ICF

Daud, M. K., Nafees, M., Ali, S., Rizwan, M., Bajwa, R. A., Shakoor, M. B., Arshad, M. U., Chatha, S. A. S., Deeba, F., Murad, W., Malook, I., \& Zhu, S. J. (2017). Drinking water quality status and contamination in Pakistan. BioMed 
Research International, 2017, 1-18. https://doi.org/10.1155 /2017/7908183.

Harshfield, E., Lantagne, D., Turbes, A., \& Null, C. (2012). Evaluating the sustained health impact of household chlorination of drinking water in rural Haiti. The American Journal of Tropical Medicine and Hygiene, 87, 786-795.

Howard G (2002). Water quality surveillance: a practical guide. United Kingdon: WEDC, Loughborough University. https://www.amazon.com/Water-Quality-Surveillancepractical-guide/dp/1843800039. Accessed Oct 2017.

Hsieh, J. L., Nguyen, T. Q., Matte, T., \& Ito, K. (2015). Drinking water turbidity and emergency department visits for gastrointestinal illness in New York City, 2002-2009. PLoS One, 10, $\mathrm{e} 0125071$.

Luoto, J., Najnin, N., Mahmud, M., Albert, J., Islam, M. S., Luby, S., Unicomb, L., \& Levine, D. I. (2011). What point-of-use water treatment products do consumers use? Evidence from a randomized controlled trial among the urban poor in Bangladesh. PLoS One, 6, e26132.

Mann, A. G., Tam, C. C., Higgins, C. D., \& Rodrigues, L. C. (2007). The association between drinking water turbidity and gastrointestinal illness: a systematic review. BMC Public Health, 7, 256. https://doi.org/10.1186/1471-2458-7-256.

Mengesha A, Wubshet M, Gelaw B (2017). A survey of bacteriological quality of drinking water in North Gondar. The Ethiopian Journal of Health Development, 18(2):112-115.

Mengistie, B., Berhane, Y., \& Worku, A. (2013). Household water chlorination reduces incidence of diarrhea among under-five children in rural Ethiopia: a cluster randomized controlled trial. PLoS One, 8, e77887.

Messer, J. W., \& Dufour, A. P. (1998). A rapid, specific membrane filtration procedure for enumeration of enterococci in recreational water. Applied and Environmental Microbiology, 64, 678-680.

Metcalfe, C., Murray, C., Collins, L., \& Furgal, C. (2011). Water quality and human health in indigenous communities in Canada. Global Bioethics, 24, 91-94.

MOFED (2010). Growth and Transformation Plan (GTP) 2010/11-2014/15: In, Ministry of finance and economic development(MoFED), Federal democratic republic of Ethiopia, Addis Ababa, Ethiopia. https://faolex. faoorg/eth144893. Accessed Dec 2017.

Mohamed, H., Brown, J., Njee, R. M., Clasen, T., Malebo, H. M., \& Mbuligwe, S. (2015). Point-of-use chlorination of turbid water: results from a field study in Tanzania. Journal of Water and Health, 13, 544-552.

Myint, S. L. T., Myint, T., Aung, W. W., Wai, K. T. (2015). Prevalence of household drinking-water contamination and of acute diarrhoeal illness in a periurban community in Myanmar. WHO South-East Asia J Public Health, 4(1-2), 62-68.

Nelson, K. L., Levy, K., Eisenberg, J. N. S., \& Hubbard, A. (2012). Rethinking indicators of microbial drinking water quality for health studies in tropical developing countries: case study in Northern Coastal Ecuador. The American Journal of Tropical Medicine and Hygiene, 86, 499-507. https://doi.org/10.4269/ajtmh.2012.11-0263.

Pant, N. D., Poudyal, N., \& Bhattacharya, S. K. (2016). Bacteriological quality of bottled drinking water versus municipal tap water in Dharan municipality, Nepal. Journal of Health, Population, and Nutrition, 35, 17.
Quick, R. E., Kimura, A., Thevos, A., et al. (2002). Diarrhea prevention through household-level water disinfection and safe storage in Zambia. The American Journal of Tropical Medicine and Hygiene, 66, 584-589.

Roy, S., Phetxumphou, K., Dietrich, A. M., Estabrooks, P. A., You, W., \& Davy, B. M. (2015). An evaluation of the readability of drinking water quality reports: a national assessment. Journal of Water and Health, 13, 645-653. https://doi. org/10.2166/wh.2015.194.

Sharma, H. R., Worku, W., Hassen, M., et al. (2013). Water handling practices and level of contamination between source and point-of-use in Kolladiba Town, Ethiopia. Environment \& We: An international Journal of Science \& Technology, 8, 25-35.

Simiyu, G. M., Ngetich, J., \& Esipila, T. A. (2009). Assessment of spring water quality and quantity, and health implications in Tongaren division, Nzoia River catchment, Kenya. African Journal of Ecology, 47, 99-104.

Sinclair, R. G., Rose, J. B., Hashsham, S. A., Gerba, C. P., \& Haas, C. N. (2012). Criteria for selection of surrogates used to study the fate and control of pathogens in the environment. Applied and Environmental Microbiology, 78, 1969-1977. https://doi.org/10.1128/AEM.06582-11.

Siraj, K. T., \& Rao, P. P. (2016). Review on water resources and sources for safe drinking and improved sanitation in Ethiopia. International Journal of Applied Research, 2, 78-82.

Strauss, B., King, W., Ley, A., \& Hoey, J. R. (2001). A prospective study of rural drinking water quality and acute gastrointestinal illness. BMC Public Health, 1, 8.

Tabor, M., Kibret, M., \& Abera, B. (2011). Bacteriological and physicochemical quality of drinking water and hygienesanitation practices of the consumers in Bahir Dar city, Ethiopia. Ethiopian Journal of Health Sciences, 21, 19-26.

Tadesse, D., Desta, A., Geyid, A., et al. (2010). Rapid assessment of drinking-water quality in the Federal Democratic Republic of Ethiopia: country report of the pilot project implementation in 2004-2005. Geneva: WHOUNICEF.

Tiku, S., Legesse, W., Endale, H., \& Faris, K. (2003). Factors affecting drinking water quality from source to home in Tehuledere Woreda, Northeast Ethiopia. Ethiopian Journal of Health Sciences, 13, 95-106.

Tinker, S. C., Moe, C. L., Klein, M., Flanders, W. D., Uber, J., Amirtharajah, A., Singer, P., \& Tolbert, P. E. (2010). Drinking water turbidity and emergency department visits for gastrointestinal illness in Atlanta, 1993-2004. Journal of Exposure Science \& Environmental Epidemiology, 20, 19-28.

Wei, L., Wu, Q., Zhang, J., Guo, W., Chen, M., Xue, L., Wang, J., \& Ma, L. (2017). Prevalence and genetic diversity of enterococcus faecalis isolates from mineral water and spring water in China. Frontiers in Microbiology, 8, 1109.

WHO (2003). Assessing microbial safety of drinking water improving approaches and methods: improving approaches and methods. OECD Publishing. https://doi.org/10.1787 /9789264099470-en.

WHO (Ed.). (2004). Guidelines for drinking-water quality (3rd ed.). Geneva: World Health Organization.

WHO (Ed.). (2011). Guidelines for drinking-water quality (4th ed.). Geneva: World Health Organization. 
WHO, \& UNICEF. (2006). Core questions on drinking water and sanitation for household surveys. Geneva: World Health Organization.

WHO, \& UNICEF. (2017). Progress on drinking water, sanitation, and hygiene: 2017 update and SDG baselines. Geneva: World Health Organization.
WHO/UNICEF. (2015). Progress on sanitation and drinking water. Geneva: World Health Organization.

Yasin, M., Ketema, T., \& Bacha, K. (2015). Physico-chemical and bacteriological quality of drinking water of different sources, Jimma zone, Southwest Ethiopia. BMC Research Notes, 8, 541. 